\title{
Evaluation of Opioid Modulation in Major Depressive Disorder
}

\author{
Elliot Ehrich*,', Ryan Turncliff', Yangchun Du', Richard Leigh-Pemberton', Emilio Fernandez ${ }^{2}$, Reese Jones ${ }^{2}$ \\ and Maurizio Fava ${ }^{3}$ \\ 'Research and Development, Alkermes, Inc., Waltham, MA, USA; ${ }^{2}$ University of California, San Francisco, CA, USA; ${ }^{3}$ Massachusetts General \\ Hospital, Boston, MA, USA
}

\begin{abstract}
Although opioids have known antidepressant activity, their use in major depressive disorder (MDD) has been greatly limited by risk of abuse and addiction. Our aim was to determine whether opioid modulation achieved through a combination of a $\mu$-opioid partial agonist, buprenorphine (BUP), and a potent $\mu$-opioid antagonist, samidorphan (SAM), would demonstrate antidepressant activity without addictive potential. A placebo-controlled crossover study assessed the opioid pharmacodynamic profile following escalating doses of SAM co-administered with BUP in opioid-experienced adults. A subsequent I-week, placebo-controlled, parallel-group study was conducted in subjects with MDD and an inadequate response to standard antidepressant therapy. This second study evaluated safety and efficacy of ratios of BUP/SAM that were associated with partial and with maximal blockade of opioid responses in the initial study. Pupillometry, visual analog scale assessments, and self-reported questionnaires demonstrated that increasing amounts of SAM added to a fixed dose of BUP resulted in dose-dependent reductions in objective and subjective opioid effects, including euphoria and drug liking, in opioid-experienced adults. Following 7 days of treatment in subjects with MDD, a 1 : I ratio of BUP and SAM, the ratio associated with maximal antagonism of opioid effects, exhibited statistically significant improvement vs placebo in HAM-DI7 total score $(p=0.032)$ and nearly significant improvement in Montgomery-Åsberg Depression Rating Scale (MADRS) total score $(p=0.054)$. Overall, BUP/SAM therapy was well tolerated. A combination of BUP and SAM showed antidepressant activity in subjects with MDD. Balanced agonistantagonist opioid modulation represents a novel and potentially clinically important approach to the treatment of MDD and other psychiatric disorders.

Neuropsychopharmacology (20I5) 40, |448-|455; doi: I0.1038/npp.20 I4.330; published online I4 January 2015
\end{abstract}

\section{INTRODUCTION}

Until the 1950s, opium was the primary pharmacologic treatment for melancholia (Tenore, 2008). However, following the introduction of monoamine oxidase inhibitors and tricyclic antidepressants, the clinical use of opioids for depression was largely abandoned owing to their inherent risks of abuse and addiction. Today, a variety of monoamine-based pharmacotherapies for depression are available, but the incidence of treatment-resistant depression remains stubbornly high, and new clinical approaches in this setting are greatly needed. The present work reassessed the potential utility of a more calibrated opioid modulation therapy in major depressive disorder (MDD), based on advancements in, and improved understanding of, opioid biology and therapeutics.

There is an evidence to indicate that endogenous opioids have important roles in human mood and that endogenous

\footnotetext{
* Correspondence: Dr E Ehrich, Research and Development, Alkermes, Inc., 852 Winter Street, Waltham, MA 0245I-I420, USA, Tel: + 781609 6190, Fax: + I 781 6095856 , E-mail: elliot.ehrich@alkermes.com

Received I4 November 20 I4; revised 9 December 20 I4; accepted 10 December 2014; accepted article preview online 18 December 2014
}

$\mu$ - and $\kappa$-opioid tone is dysregulated in the context of depression (Kennedy et al, 2006; Knoll and Carlezon, 2010). Opioid receptors are densely distributed in cortical regions implicated in the response to stressors, as well as the regulation and/or integration of emotionally significant stimuli, including the rostral anterior cingulate and prefrontal cortex (Kennedy et al, 2006; Eisenberger et al, 2003; Kerns et al, 2004; Ribeiro et al, 2005). The opioid system has a prominent sub-cortical regulatory role in the striatopallidal pathway (nucleus accumbens and ventral pallidum) and associated circuits (amygdala, thalamus, insular cortex), which are also involved in the processing of stressful stimuli and sadness (Bals-Kubik et al, 1993). Finally, there is post mortem evidence of endorphin deficiency in severely depressed and suicidal patients (Scarone et al, 1990; Gross-Isseroff et al, 1990; Gabilondo et al, 1995), although one study showed evidence of differential receptor affinity rather than expression (Zalsman et al, 2005).

There are no prior published reports of placebo-controlled studies of opioid agonists in the treatment of depression. In observational studies, treatment with $\mu$-opioid agonists has been associated with significant and rapid mood elevation in depression, including subjects with treatmentresistant MDD (Emrich et al, 1982; Kosten et al, 1990; Mongan and Callaway, 1990; Bodkin et al, 1995; Gerra et al, 2006; Nyhuis et al, 2008, Karp et al, 2014). It remains 
unknown whether these effects are simply attributable to the induction of drug liking or a 'high.' In other words, it is not known whether the addictive and antidepressant effects of opioids are intrinsically inseparable. If a co-administered $\mu$ antagonist was able to counteract the addictive properties of a $\mu$ agonist, without interfering with its antidepressant effects, then controlled opioid modulation via combined agonist-antagonist administration might serve as the basis for a novel pharmacotherapeutic approach with broader applicability in the treatment of MDD.

To test this hypothesis, we utilized buprenorphine (BUP), a partial $\mu$ agonist. In addition to its effects on the $\mu$-opioid receptor, BUP has also been shown to block the action of $\kappa$ agonists in in vivo pharmacology assays (Leander, 1987). BUP has shown evidence of antidepressant efficacy in MDD in observational studies (Bodkin et al, 1995; Nyhuis et al, 2008; Emrich et al, 1982; Cowan, 2003; Walsh et al, 1994, 1995; Callaway, 1996, Karp et al, 2014). BUP undergoes substantial first-pass hepatic metabolism and is therefore administered sublingually. For outpatient clinical testing, it was considered essential that BUP and the co-administered $\mu$-opioid antagonist should be available in a single-tablet formulation to ensure patient adherence with both the agonist and antagonist components of therapy and to limit the potential for abuse. A potent $\mu$-opioid antagonist with high sublingual bioavailability was therefore needed and led to the identification of samidorphan (SAM; 3-carboxamido-4-hydroxynaltrexone), which had those requisite characteristics (Wentland et al, 2005, 2009). The combination of BUP and SAM was studied first in opioid-experienced, non-depressed subjects to identify ratios of the two components that yielded intermediate and maximal blockade of $\mu$-opioid subjective and physiologic responses. A subsequent study evaluated safety, tolerability, and preliminary efficacy BUP/SAM combination therapy at the ratios identified in the initial study as an adjunctive treatment in subjects with MDD and an inadequate response to standard antidepressant therapy (SSRI or SNRI).

\section{METHODS}

\section{Study 1: BUP/SAM Dose-Ratio Study in Healthy Opioid-Experienced Adults}

The objective of this first study was to evaluate the effect of increasing doses of SAM co-administered with a fixed dose of BUP on measures of opioid pharmacodynamics. This was a single-center, double-blind, randomized and placebo-controlled crossover study. Thirteen subjects were recruited at a single-center psychiatric hospital. Included subjects were healthy adults who were opioid-experienced, but infrequently using (ie, not-addicted) and non-treatment-seeking. They passed screenings that included naloxone and BUP challenge doses.

Following screening, subjects were enrolled into two sequential cohorts, six subjects in Cohort 1 (BUP/SAM $8 / 0 \mathrm{mg}, 8 / 1 \mathrm{mg}$, and $8 / 4 \mathrm{mg}$ ) and seven in Cohort 2 (BUP/ SAM $8 / 0 \mathrm{mg}, 8 / 8 \mathrm{mg}$, and $8 / 16 \mathrm{mg}$ ) (Figure 1). The three sublingual doses of study medication in each cohort were administered in a randomized sequence. Doses were separated by 7 - to 12-day washout periods and were blinded within each cohort. Safety was monitored by adverse event (AE), vital signs, laboratory and physical examination findings, electrocardiogram (ECG), and pulse oximetry. Following study drug administration, subjects were assessed for both physiologic (pupillometry) and subjective opioid effects. Subjective effects assessed included 'high', 'drug effect', 'good effects', 'bad effects', 'drug linking', and 'feeling sick', assessed on a $100 \mathrm{~mm}$ visual analog scale (VAS) from 'not at all' to 'extremely' (Harris et al, 2004). Subjective effects were also assessed using a 16-item opiate agonist scale with each rated by the subject on an intensity scale of $0-4$ with 0 as 'no effect' and 4 as 'maximum effect' as described previously (Harris et al, 2004).

\section{Study 2: BUP/SAM Study in Subjects with MDD}

The objectives of this randomized, double-blind, placebocontrolled, parallel-group, multiple-dose study were to evaluate the safety, tolerability, and preliminary efficacy of BUP/SAM at dose levels and BUP:SAM dose ratios associated with intermediate and maximal blockade Studyl. The study enrolled 32 adult subjects with MDD, using DSM-IV-TR criteria, with a current episode of $>8$ weeks and an inadequate $(<50 \%)$ response to at least 8 weeks of an adequate and stable dose of an antidepressant (SSRI or SNRI) in the current episode. Exclusion criteria included bipolar disorder, psychosis, personality disorder, and risk of suicide. Subjects with a diagnosis of alcohol or illicit drug dependence within 12 months prior to screening were also excluded. Subjects with nicotine dependence were not excluded.

Eligible subjects were randomized to three treatment groups: BUP:SAM 8:1 dose-ratio treatment group $(n=14)$; BUP:SAM $1: 1$ dose-ratio treatment group $(n=14)$; and placebo $(n=4)$ (Figure 1). As this was the very first multi-dose study of the BUP/SAM combination, a key objective of the study was to obtain safety experience in depressed subjects. As such, more subjects were assigned to active treatment than placebo to provide sufficient exposure to support larger clinical efficacy studies. All patients remained on SSRI or SNRI background therapy throughout the treatment period.

All subjects received study drug for 7 days. In the BUP:SAM $8: 1$ dose-ratio treatment group, subjects received BUP/SAM $2 \mathrm{mg} / 0.25 \mathrm{mg}$ for 3 days and BUP/SAM $4 \mathrm{mg} / 0.5 \mathrm{mg}$ for 4 days (referred to as the $8: 1$ treatment group). In the BUP:SAM 1:1 dose-ratio treatment group, subjects received BUP/SAM $4 \mathrm{mg} /$ $4 \mathrm{mg}$ and BUP/SAM $8 \mathrm{mg} / 8 \mathrm{mg}$ over the same time periods (referred to as the $1: 1$ treatment group). Subjects were evaluated daily during the treatment period. Safety assessments included AEs, vital signs, laboratory findings, ECG, daily VAS analyses of 'high' and 'sedation' using methodology as described above for Study 1, the Addiction Research Center Inventory-Morphine Benzedrine Group (ARCI-MBG) (Haertzen, 1974) and the Columbia Suicide Severity Rating Scale (C-SSRS) (Posner et al, 2011). Efficacy assessments including the Hamilton Depression Rating Scale (HAM-D17) (Hamilton, 1960) and the Montgomery-Åsberg Depression Rating Scale (MADRS) (Montgomery and Asberg, 1979) were collected at baseline and at day 7 .

\section{Statistical Analyses}

Safety, pharmacodynamic, and efficacy data were collected per time point and per cohort/dose level and analyzed using descriptive statistics. Maximum decrease in pupil 

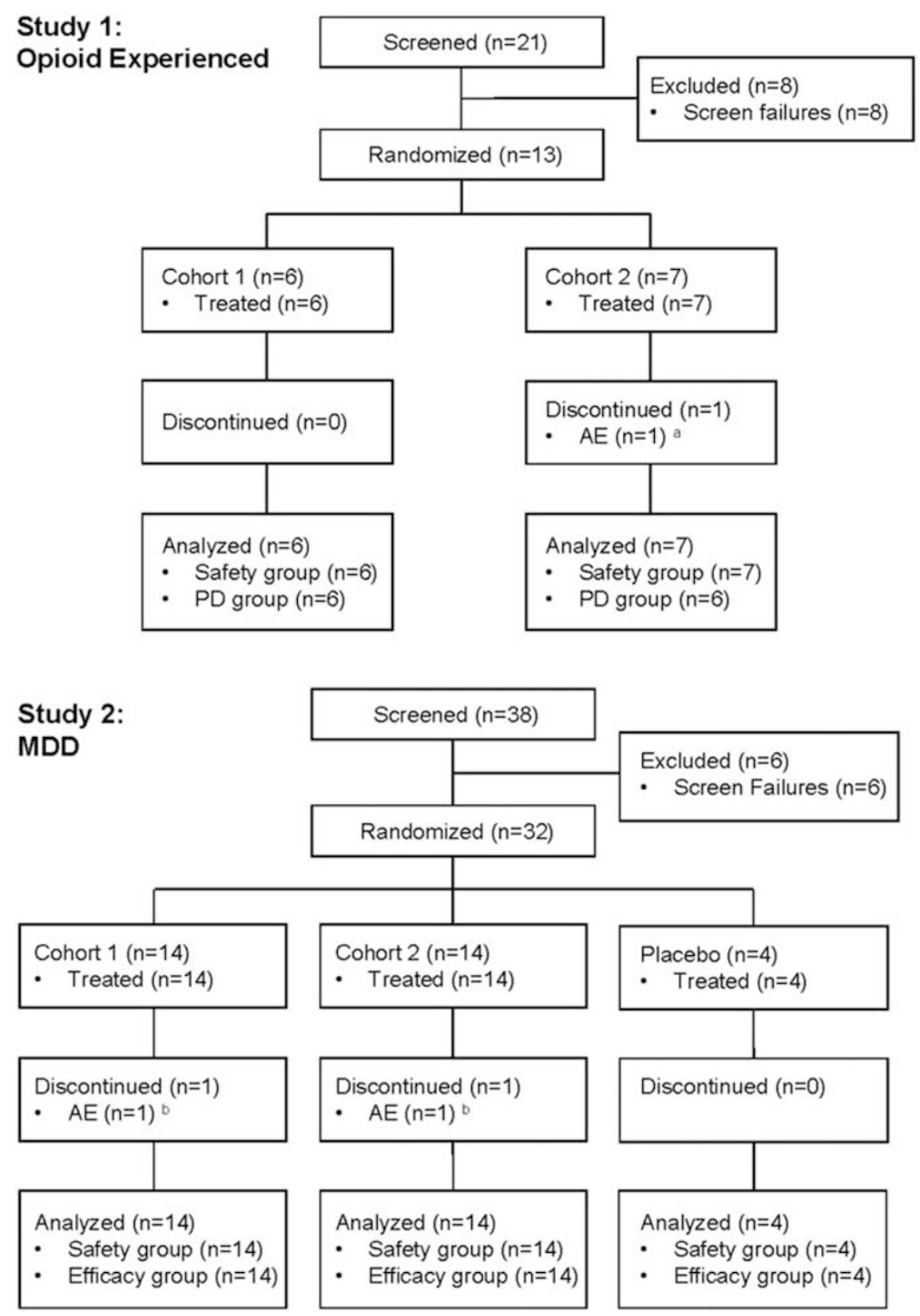

Figure I CONSORT flow diagrams. In Study I, opioid-experienced adults received single doses of BUP/SAM 8/0 mg, 8/I mg, and 8/4 mg in Cohort I and $8 / 0 \mathrm{mg}, 8 / 8 \mathrm{mg}$, and 8/16 mg in Cohort 2, respectively. In Study 2, adults with MDD received BUP/SAM 2/0.25 mg QD for 3 days and 4/0.5 mg QD for 4 days in Cohort I, and BUP/SAM 4/4 mg QD for 3 days and 8/8 mg QD for 4 days in Cohort 2. (a) Withdrew in first session because oforal cavity abscess; (b) One subject each in Cohort I and Cohort 2 withdrew after the first dose of study medication because of vomiting.

diameters, maximum increase in VAS scores, and their means were evaluated in both studies.

In the first study, $\mu$ opioid blockade was primarily assessed via VAS scores of 'high,' 'liking', and 'good,' and a statistically significant difference (one-sided $p<0.05$ ) in the predose and peak post-dose VAS scores for a dosing session was considered to be an evidence of incomplete blockade. Pairwise comparisons of active treatment $v s$ placebo were performed using a $t$-test. Adjacent doses were compared using a $t$-test and step-down Bonferroni adjustment for the dose comparison. Subjective measurements were analyzed using a paired $t$-test for change from baseline within a group and $t$-tests for pairwise comparisons $v s$ BUP/SAM
$8 \mathrm{mg} / 0 \mathrm{mg}$. Change from baseline in subjective symptoms was calculated based the 16 opioid agonist item scores for the Subjective Symptoms Questionnaire and change in the 3-h pre-dose vs post-dose scores (Supplementary Table 1).

To analyze the efficacy of BUP/SAM therapy in MDD, mean decreases from baseline in HAM-D17 and MADRS total scores after 7 days of therapy were calculated, and $p$-values were generated from Exact Wilcoxon tests.

\section{Ethics}

The two studies described here (ClinicalTrials.gov identifiers, NCT01046539 and NCT01381107) were conducted in 
Table I Demographics and Baseline Characteristics

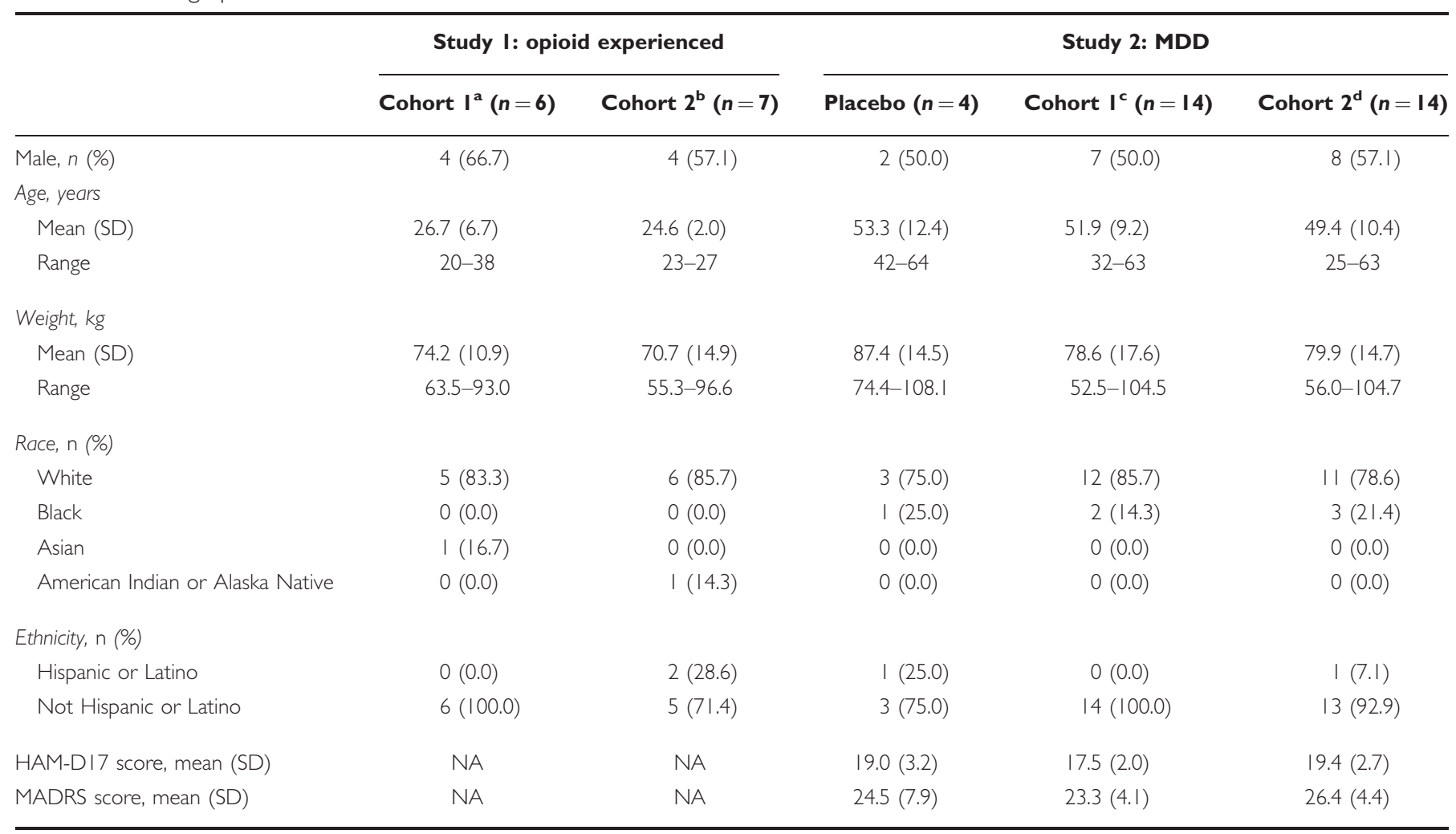

Abbreviations: HAM-D, Hamilton Depression Scale; MADRS, Montgomery-Åsberg Depression Rating Scale; MDD, major depressive disorder; NA, not applicable. 'Buprenorphine/samidorphan (BUP/SAM) $8 / 0 \mathrm{mg}, 8 / \mathrm{lmg}$, and $8 / 4 \mathrm{mg}$ (order randomized).

bBUP/SAM $8 / 0 \mathrm{mg}, 8 / 8 \mathrm{mg}$, and $8 / 16 \mathrm{mg}$ (order randomized).

${ }^{\circ}$ BUP/SAM $2 / 0.25 \mathrm{mg} \rightarrow 4 / 0.5 \mathrm{mg}(8 / 1$ ratio $(\mathrm{w} / \mathrm{w}))$.

${ }^{\mathrm{d} B U P: S A M} 4 / 4 \mathrm{mg} \rightarrow 8 / 8 \mathrm{mg}(\mathrm{I}:$ I ratio $(\mathrm{w} / \mathrm{w}))$.

accordance with the Declaration of Helsinki, International Conference on Harmonization Good Clinical Practice guidelines and applicable federal, state and local laws of the United States. Each study followed a protocol reviewed by an institutional review board, and all subjects provided written informed consent prior to receiving study treatments. BUP is a Schedule III medication under the Controlled Substances Act and was stored in accordance with applicable state and federal restrictions.

\section{RESULTS}

\section{Subjects}

Demographics and baseline characteristics were relatively well matched between cohorts in both studies (Table 1). One subject in Study 1, Cohort 2 withdrew owing to an oral cavity abscess after the first dosing session and was excluded from pharmacodynamic analyses.

\section{Calibrating BUP/SAM for $\mu$-Blockade in Opioid-Experienced Adults}

Change in pupil diameter I response to BUP and BUP/SAM was assessed as a physiologic measure of $\mu$-opioid blockade.
Mean pupil diameters decreased by $\sim 50 \%$ within $4 \mathrm{~h}$ of BUP/SAM $8 \mathrm{mg} / 0 \mathrm{mg}$ administration and reverted back to baseline levels over the following $20 \mathrm{~h}$ (Figure 2). Coadministration of SAM-attenuated this BUP-mediated miosis in a dose-dependent fashion, with maximal inhibition of the constriction occurring in the BUP/SAM $8 \mathrm{mg} /$ $8 \mathrm{mg}$ and $8 \mathrm{mg} / 16 \mathrm{mg}$ dosing sessions $(p \leqslant 0.001 v s$ BUP/ SAM $8 \mathrm{mg} / 0 \mathrm{mg}$ for all comparisons).

VAS scores were used to assess the effect of SAM on the subjective experience of BUP. Analogous to the pupil diameter results, co-administration of SAM also dosedependently decreased VAS scores for post-administration 'high effects' and 'liking' (Figure 2), as well as 'drug effects,' 'good effects,' 'bad effects', and 'feeling sick' (Supplementary Figure 1). Significant reductions in opioid agonist scores on the Subject Symptom Questionnaire were similarly reported with increasing dosages of SAM (Supplementary Table 1).

\section{BUP/SAM in Subjects with MDD}

Subjects with MDD in the 8:1 treatment group consistently self-reported greater mean VAS scores, for feeling high and feeling sedation following study drug administration compared with subjects in the $1: 1$ group (Figure 3). No 

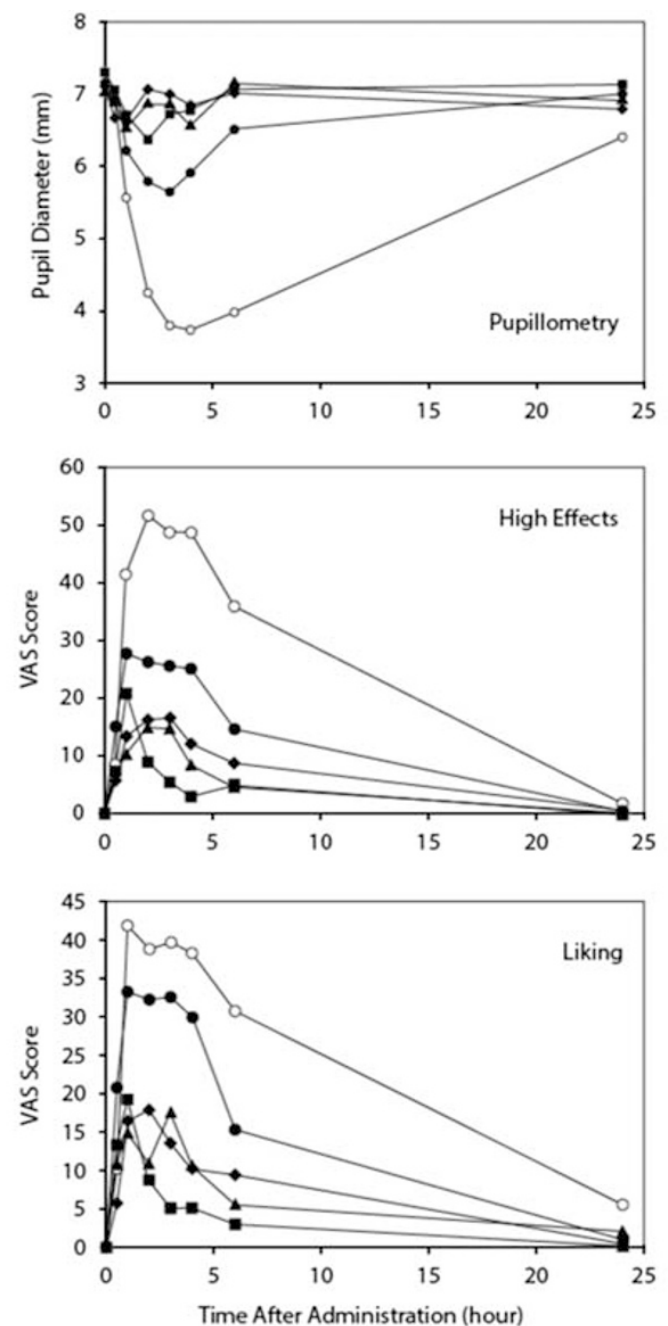

\begin{tabular}{|llll|}
\hline - BUP/SAM $8 / 0 \mathrm{mg}$ & - BUP/SAM $8 / 1 \mathrm{mg}$ & - BUP/SAM $8 / 4 \mathrm{mg}$ \\
- BUP/SAM $8 / 8 \mathrm{mg}$ & A BUP/SAM $8 / 16 \mathrm{mg}$ & \\
\hline
\end{tabular}

Figure 2 Pupillometry and VAS analyses in healthy opioid-experienced adults.

consistent changes in mean VAS scores were discernible after dose escalation on day 3 in the $8: 1$ treatment group (BUP/SAM $2 \mathrm{mg} / 0.25 \mathrm{mg}$ qd $3 \mathrm{~d} \rightarrow 4 \mathrm{mg} / 0.5 \mathrm{mg}$ qd $4 \mathrm{~d}$ ) or in the $1: 1$ treatment group (BUP/SAM $4 \mathrm{mg} / 4 \mathrm{mg}$ qd $3 \mathrm{~d} \rightarrow$ $8 \mathrm{mg} / 8 \mathrm{mg}$ qd $4 \mathrm{~d}$ ).

Preliminary efficacy was assessed by change from baseline in HAM-D17 and MADRS. After 7 days of once-daily administration, both BUP:SAM ratios resulted in improvements in HAM-D17 and MADRS scores (Figure 4). For HAM-D17, baseline scores (SD) were 19.0(3.2), 17.5(2.0), and 19.4(2.7) and the changes from baseline were $-1.0(4.2)$, $-5.0(6.1)$, and $-6.7(3.4)$ were for the placebo, $8: 1$, and $1: 1$ treatment groups, respectively. For MADRS, baseline scores (SD) were 24.5(7.9), 23.3(4.1), and 26.4(4.4), and the changes from baseline were $-3.5(5.8),-8.5(7.4)$, and $-11.5(6.5)$ for the placebo, $8: 1$, and $1: 1$ treatment groups, respectively. For the $1: 1$ treatment group, the difference from placebo was significant with the HAM-D17 $(p=0.032)$ and trended towards significance with the MADRS $(p=0.054)$.
Safety

The most common treatment-emergent AEs across both studies were dizziness, nausea, and vomiting (Table 2 and Supplementary Table 2). All AEs resolved within 24-72 h without investigator intervention. Nausea and vomiting were observed in both opioid-experienced subjects (Study 1) and opioid-naive MDD subjects (Study 2), although the incidence was lower in subjects who received higher levels of SAM as compared with BUP alone. Dizziness was more commonly observed in subjects with MDD relative to healthy opioidexperienced adults. No clinically significant changes were observed in peripheral blood oxygen saturation (Study 1), or blood chemistries, urinalysis panels, heart rate, blood pressure, respiration rate, or ECG in either study.

In subjects with MDD, no consistent differences were observed pre-dose vs post-dose on the ARCI-MBG and the C-SSRS.

\section{DISCUSSION}

This report presents the first placebo-controlled study of an agent with an opioidergic mechanism in the treatment of MDD. In an initial clinical study, the effects of single-dose BUP/SAM combinations were examined in healthy, nondepressed, opioid-experienced adults. Results demonstrated that the addition of increasing amounts of SAM to a fixed amount of BUP resulted in dose-dependent reductions in post-administration miosis, an objective measure of $\mu$-opioid pharmacodynamics, which paralleled dose-dependent reductions in subjective measures, including drug liking, drug high, and sedation. Intermediate and maximal levels of blockade were observed when BUP and SAM were administered at ratios of $\sim 8: 1$ and $1: 1$, respectively.

Following the calibration of BUP and SAM in opioidexperienced adults, the second study evaluated the $8: 1$ and $1: 1$ dose ratios as adjunctive therapies in subjects with MDD who demonstrated inadequate response to SSRI or SNRI treatment. Antidepressant effects were greatest in subjects who received BUP and SAM at the $1: 1$ ratio, which was the ratio associated with maximal blockade of opioid effects. Thus, following 7 days of once daily BUP/SAM at a $1: 1$ ratio, subjects with MDD exhibited statistically significant improvement in HAM-D17 total score $(p=0.032)$ and nearly significant improvement in MADRS total score $(p=0.054)$ vs placebo. The magnitude of effect at 1 week with the $1: 1$ ratio was substantial, with an effect size of 1.49 and 1.29 for HAMD17 and MADRS, respectively, using Cohen's $d$ (Cohen, 1988).

Changes in VAS scales and the Subjective Symptoms Questionnaire agonist effects scores in the opioid-experienced adults, as well as in the depressed patients' VAS scales and addiction scores (ARCIMBG), suggest that SAM at the $1: 1$ ratio was effective in blocking the addictive potential of BUP. Furthermore, no evidence of opioid withdrawal was observed following abrupt discontinuation of therapy.

Overall, the safety and tolerability profile of BUP/SAM in both subject populations was favorable. The most commonly reported AEs were dizziness, nausea, and vomiting, consistent with opioid class effects. The incidences of nausea and vomiting in opioid-experienced adults were higher with BUP monotherapy (BUP/SAM $8 \mathrm{mg} / 0 \mathrm{mg}$ ) compared with the BUP/SAM combination, indicating 
"High Effects"
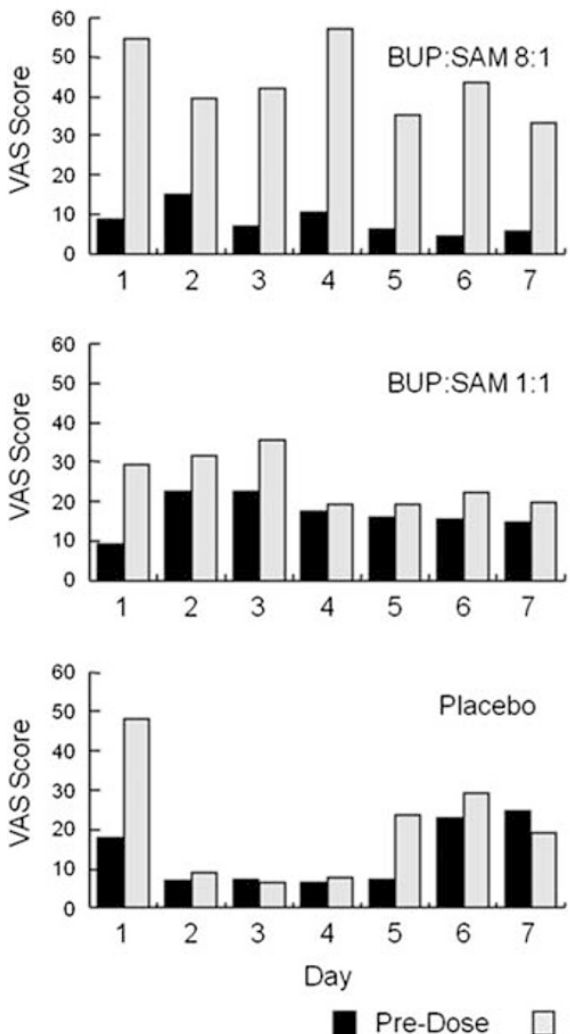

"Sedation"
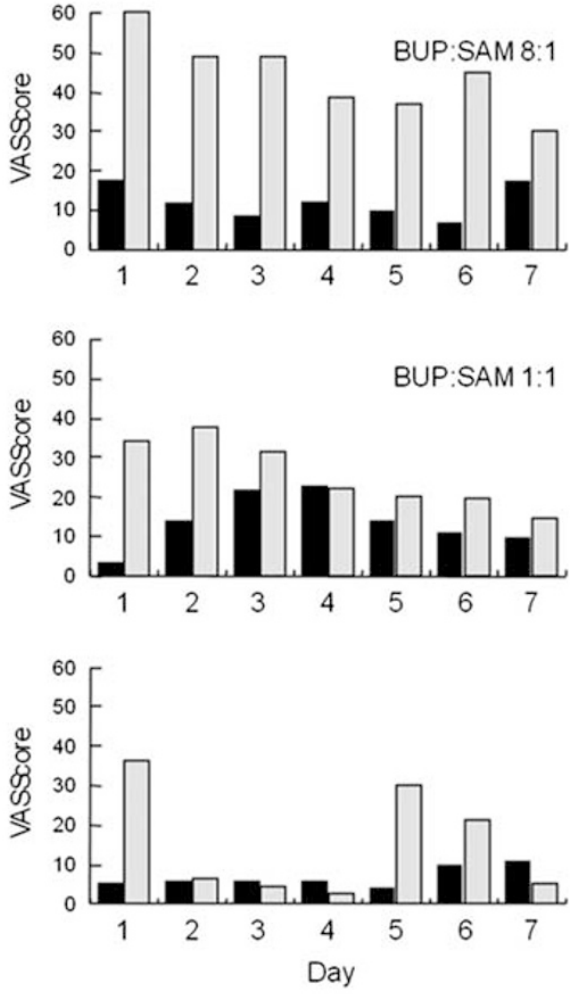

Figure 3 VAS analyses in MDD patients. Note: combination of buprenorphine and samidorphan in 8: I ratio is noted as BUP:SAM 8: I; combination of buprenorphine and samidorphan in a $1:$ I ratio is noted as BUP:SAM I : I.

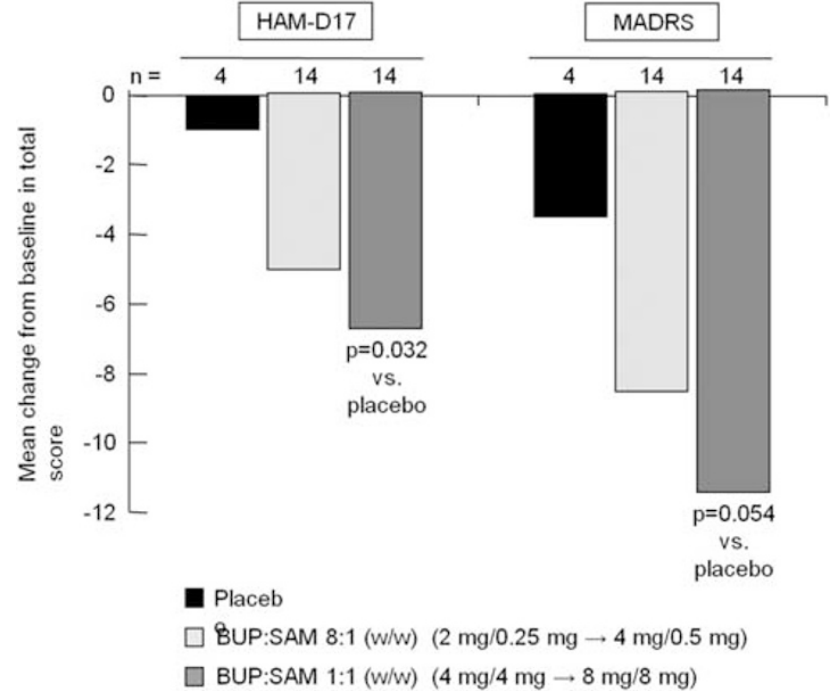

Figure 4 Efficacy of BUP/SAM therapy in MDD. Displayed are mean decreases from baseline in HAM-DI7 (left) and MADRS (right) total scores after 7 days of therapy. P-values are from Exact Wilcoxon tests and are based on observed data.

attenuation of BUP's gastrointestinal effects by SAM. No respiratory depression was observed in any dosing group.

The observation of robust antidepressant activity in subjects receiving the $1: 1$ ratio, ie, the ratio associated with maximal antagonism of $\mu$-opioid effects, was surprising.
It had been anticipated that the $8: 1$ ratio, which retains a larger degree of $\mu$-opioid agonism than the $1: 1$ ratio, would demonstrate the greatest antidepressant response. Agonism of $\mu$-opioid receptors has been correlated with increases in dopamine levels, enhancement of hedonic tone, and sense of contentment, which together would be expected to confer antidepressant activity (Lutz and Kieffer, 2013). Post mortem studies of patients with depression and suicide have shown evidence of increased $\mu$-opioid receptor expression consistent with an endogenous endorphin insufficiency (Scarone et al, 1990; Gross-Isseroff et al, 1990; Gabilondo et al, 1995). Similarly, PET studies reveal multiple focal deficits in endogenous opioid activity in depressed patients and with induced sadness states compared with controls (Kennedy et al, 2006; Ribeiro et al, 2005; Bencherif et al, 2002; Zubieta et al, 2003).

The robust antidepressant activity of the $1: 1$ ratio implies that substantial exogenous augmentation in $\mu$-opioid agonist activity may not to be necessary to elicit a clinically meaningful response in the treatment of depression. Rather, our results indicate that simultaneous administration of an opioid agonist and antagonist with opposing pharmacologic activities of similar magnitude, ie, a 'balanced' agonistantagonist opioid modulation, may be sufficient and optimal to normalize dysregulated or impaired endogenous opioidergic tone may in the context of depression, and hence yield therapeutic benefit.

An alternative, but not mutually exclusive, explanation of these results invokes the $\kappa$-opioid system. In contradistinction 
Table 2 Treatment-Emergent Adverse Events

\begin{tabular}{|c|c|c|c|c|c|c|c|}
\hline \multirow[t]{2}{*}{ BUP/SAM dosage } & \multicolumn{4}{|c|}{ Study I: opioid experienced } & \multicolumn{3}{|c|}{ Study 2: MDD } \\
\hline & $8 / 0 \mathrm{mg}$ & $8 / 4 \mathrm{mg}$ & $8 / 8 \mathrm{mg}$ & $8 / 16 \mathrm{mg}$ & 0/0 mg placebo & $\begin{array}{c}2 / 0.25 \mathrm{mg} \\
\downarrow \\
4 / 0.5 \mathrm{mg}\end{array}$ & $\begin{array}{c}4 / 4 \mathrm{mg} \\
\downarrow \\
8 / 8 \mathrm{mg}\end{array}$ \\
\hline$N$ & 12 & 6 & 6 & 7 & 4 & 14 & 14 \\
\hline \multicolumn{8}{|l|}{ Patients with $A E, \mathrm{n}(\%)$} \\
\hline Nausea & $7(58.3)$ & I (16.7) & I (I6.7) & I (I4.3) & I (25.0) & $4(28.6)$ & $3(21.4)$ \\
\hline Vomiting & $6(50.0)$ & I (16.7) & I (I6.7) & $2(28.6)$ & $0(0.0)$ & $4(28.6)$ & $2(14.3)$ \\
\hline Constipation & $0(0.0)$ & $0(0.0)$ & $0(0.0)$ & $0(0.0)$ & $0(0.0)$ & $2(14.3)$ & $3(21.4)$ \\
\hline Sedation & $0(0.0)$ & $0(0.0)$ & $0(0.0)$ & $0(0.0)$ & $0(0.0)$ & $3(21.4)$ & I (7.1) \\
\hline Fatigue & । (8.3) & | (16.7) & $0(0.0)$ & | (I4.3) & $0(0.0)$ & $2(14.3)$ & I (7. I) \\
\hline
\end{tabular}

Abbreviations: AE, adverse event; BUP, buprenorphine; MDD, major depressive disorder; SAM, samidorphan.

Incidence of the most common treatment-emergent AEs are listed for Study I and Study 2. Events are listed in descending order of frequency observed in the active treatment groups of Study 2. There were no AEs reported in the $8 / 1 \mathrm{mg}$ group.

to $\mu$-receptor agonism, $\kappa$-receptor agonism has been associated with adverse effects on mood in humans (Pfeiffer et al, 1986; Wadenberg, 2003) and rodents (Carlezon et al, 2009; Mague et al, 2003). On the basis of the results in animal models, it has been proposed that a $\kappa$-opioid antagonist might function therapeutically as an antidepressant in humans (Knoll and Carlezon, 2010). In addition to its effects on the $\mu$-opioid receptor, BUP has also been shown to block the action of $\kappa$ agonists in in vivo pharmacology assays and has been characterized in vitro to be a $\kappa$ partial agonist with low intrinsic activity (Leander, 1987; Wentland et al, 2009). Indeed, functional $\kappa$ antagonism has been proposed as a mechanism underlying the efficacy of BUP/naltrexone combination therapy for opioid dependence (Gerra et al, 2006; McCann, 2008; Rothman et al, 2000). Further investigation in humans and animal model systems utilizing imaging, pharmacologic, and other probes will be needed to understand the relative contribution of endogenous dynorphin blockade and endogenous $\mu$-opioid modulation to the observed antidepressant activity with BUP/SAM.

Limitations of these studies in this report include short duration of the clinical study in depression and the small number of subjects evaluated. VAS scales were exploratory in largely opioid-naive depressed subjects as they are not validated in this population. Further study with larger sample size and longer duration of treatment is needed to quantify the magnitude and durability of treatment effect for the BUP/SAM combination in depression.

The results of this work suggest that BUP/SAM may provide an important treatment option for patients with MDD and an inadequate response to SSRI or SNRI therapy or with treatment-resistant depression. Beyond MDD, a growing body of evidence indicates that dysregulation of endogenous opioids and their receptors may be involved in other neuropsychological processes and their psychiatric correlates (Ribeiro et al, 2005). Given the fundamental involvement of endogenous opioids in stress and the neurocircuitry of emotion, opioid modulation via a balanced agonist-antagonist combination may merit evaluation in a variety of psychiatric disorders, including borderline per- sonality disorder, autism, posttraumatic stress disorder, and obsessive-compulsive disorder.

\section{FUNDING AND DISCLOSURE}

Drs Ehrich, Turncliff, Du, and Leigh-Pemberton are employees of Alkermes, Inc.; Dr Fava is a consultant to Alkermes. This study was supported in part by the National Center for Research Resources and the National Center for Advancing Translational Sciences, National Institutes of Health, through UCSF-CTSI Grant Number UL1 RR024131 and the National Institute on Drug Abuse, National Institutes of Health through NIDA Grant Number N01DA-6-8867 and NIDA Grant Number R01DA031000. The remaining authors declare no conflict of interest.

\section{ACKNOWLEDGEMENTS}

The authors would like to thank Nora Chiang, $\mathrm{PhD}$ and David McCann, PhD of NIDA; Adriana Manari of UCSF; Michael Thase, MD of University of Pennsylvania; Madhukar Trivedi, MD of University of Texas Southwestern; J Alexander Bodkin, MD of Harvard-McLean Hospital for their contributions to study design and data interpretation and to Janet Ransom of Fast-Track Drugs and Biologics, LLC for her contribution to the data analysis. We would also like to acknowledge David Norris, $\mathrm{PhD}$ for editorial assistance. The study in opioid experienced adults was previously presented at The College on Problems of Drug Dependence Annual Meeting, 18-23 June 2011; Hollywood, Florida. The study in subjects with MDD was previously presented at the New Clinical Drug Evaluation Unit Annual Meeting, 29 May-1 June 2012; Phoenix, Arizona.

\section{REFERENCES}

Bals-Kubik R, Ableitner A, Herz A, Shippenberg TS (1993). Neuroanatomical sites mediating the motivational effects of opioids as mapped by the conditioned place preference paradigm in rats. J Pharmacol Exp Ther 264: 489-495. 
Bencherif B, Fuchs PN, Sheth R, Dannals RF, Campbell JN, Frost JJ (2002). Pain activation of human supraspinal opioid pathways as demonstrated by [11C]-carfentanil and positron emission tomography (PET). Pain 99: 589-598.

Bodkin JA, Zornberg GL, Lukas SE, Cole JO (1995). Buprenorphine treatment of refractory depression. J Clin Psychopharmacol 15: 49-57.

Callaway E (1996). Buprenorphine for depression: the unadoptable orphan. Biol Psychiatry 39: 989-990.

Carlezon WA Jr., Beguin C, Knoll AT, Cohen BM (2009). Kappaopioid ligands in the study and treatment of mood disorders. Pharmacol Ther 123: 334-343.

Cohen J (1988). Statistical Power Analysis for the Behavioral Sciences. 2nd edn. Lawrence Erlbaum: Hillsdale, NJ, USA.

Cowan A (2003). Buprenorphine: new pharmacological aspects. Int I Clin Pract Suppl 133: 3-8.

Eisenberger NI, Lieberman MD, Williams KD (2003). Does rejection hurt? An FMRI study of social exclusion. Science 302: 290-292.

Emrich HM, Vogt P, Herz A (1982). Possible antidepressive effects of opioids: action of buprenorphine. Ann NY Acad Sci 398: 108-112.

Gabilondo AM, Meana JJ, Garcia-Sevilla JA (1995). Increased density of $\mu$-opioid receptors in the postmortem brain of suicide victims. Brain Res 682: 245-250.

Gerra G, Fantoma A, Zaimovic A (2006). Naltrexone and buprenorphine combination in the treatment of opioid dependence. J Psychopharmacol 20: 806-814.

Gross-Isseroff R, Dillon KA, Israeli M, Biegon A (1990). Regionally selective increases in mu opioid receptor density in the brains of suicide victims. Brain Res 530: 312-316.

Haertzen CA (1974). Subjective effects of narcotic antagonists. In: Braude MC, Harris LS, May EL, Smith JP, Villarreal JE (eds) Narcotic Antagonists. Raven Press: New York, NY, USA, pp 383-398.

Hamilton M (1960). A rating scale for depression. J Neurol Neurosurg Psychiatry 23: 56-62.

Harris DS, Mendelson JE, Lin ET, Upton RA, Jones R (2004). Pharmacokinetics and subjective effects of sublingual buprenorphine, alone or in combination with naloxone. Lack of dose proportionality. Clin Pharmacokinet 43: 329-340.

Karp JF, Butler MA, Begley AE, Miller MD, Lenze EJ, Blumberger $\mathrm{DM}$ et al (2014). Safety, tolerability, and clinical effect of lowdose buprenorphine for treatment-resistant depression in midlife and older adults. J Clin Psychiatry 75: e785-e793.

Kennedy SE, Koeppe RA, Young EA, Zubieta JK (2006). Dysregulation of endogenous opioid emotion regulation circuitry in major depression in women. Arch Gen Psychiatry 63: 1199-1208.

Kerns JG, Cohen JD, MacDonald AW 3rd, Cho RY, Stenger VA, Carter CS (2004). Anterior cingulate conflict monitoring and adjustments in control. Science 303: 1023-1026.

Knoll AT, Carlezon WA Jr (2010). Dynorphin, stress, and depression. Brain Res 1314: 56-73.

Kosten TR, Morgan C, Kosten TA (1990). Depressive symptoms during buprenorphine treatment of opioid abusers. J Subst Abuse Treat 7: 51-54.

Leander JD (1987). Buprenorphine has potent kappa opioid receptor antagonist activity. Neuropharmacology 26: $1445-1447$.

Lutz PE, Kieffer BL (2013). Opioid receptors: distinct roles in mood disorders. Trends Neurosci 36: 195-206.

Mague SD, Pliakas AM, Todtenkopf MS, Tomasiewicz HC, Zhang Y, Stevens WC Jr. et al (2003). Antidepressant-like effects of kappa-opioid receptor antagonists in the forced swim test in rats. J Pharmacol Exp Ther 305: 323-330.
McCann DJ (2008). Potential of buprenorphine/naltrexone in treating polydrug addiction and co-occurring psychiatric disorders. Clin Pharmacol Ther 83: 627-630.

Mongan L, Callaway E (1990). Buprenorphine responders. Biol Psychiatry 28: 1078-1080.

Montgomery SA, Asberg M (1979). A new depression scale designed to be sensitive to change. Br J Psychiatry 134: 382-389.

Nyhuis PW, Gastpar M, Scherbaum N (2008). Opiate treatment in depression refractory to antidepressants and electroconvulsive therapy. J Clin Psychopharmacol 28: 593-595.

Pfeiffer A, Brantl V, Herz A, Emrich HM (1986). Psychotomimesis mediated by kappa opiate receptors. Science 233: 774-776.

Posner K, Brown GK, Stanley B, Brent DA, Yershova KV, Oquendo MA et al (2011). The Columbia-Suicide Severity Rating Scale: initial validity and internal consistency findings from three multisite studies with adolescents and adults. Am J Psychiatry 168: 1266-1277.

Ribeiro SC, Kennedy SE, Smith YR, Stohler CS, Zubieta JK (2005). Interface of physical and emotional stress regulation through the endogenous opioid system and mu-opioid receptors. Prog Neuropsychopharmacol Biol Psychiatry 29: 1264-1280.

Rothman RB, Gorelick DA, Heishman SJ, Eichmiller PR, Hill BH, Norbeck J et al (2000). An open-label study of a functional opioid kappa antagonist in the treatment of opioid dependence. J Subst Abuse Treat 18: 277-281.

Scarone S, Gambini O, Calabrese G, Sacerdote P, Bruni M, Carucci M et al (1990). Asymmetrical distribution of beta-endorphin in cerebral hemispheres of suicides: preliminary data. Psychiatry Res 32: 159-166.

Tenore PL (2008). Psychotherapeutic benefits of opioid agonist therapy. J Addict Dis 27: 49-65.

Wadenberg ML (2003). A review of the properties of spiradoline: a potent and selective kappa-opioid receptor agonist. CNS Drug Rev 9: 187-198.

Walsh SL, Preston KL, Bigelow GE, Stitzer ML (1995). Acute administration of buprenorphine in humans: partial agonist and blockade effects. J Pharmacol Exp Ther 274: 361-372.

Walsh SL, Preston KL, Stitzer ML, Cone EJ, Bigelow GE (1994). Clinical pharmacology of buprenorphine: ceiling effects at high doses. Clin Pharmacol Ther 55: 569-580.

Wentland MP, Lu Q, Lou R, Bu Y, Knapp BI, Bidlack JM (2005). Synthesis and opioid receptor binding properties of a highly potent 4-hydroxy analogue of naltrexone. Bioorg Med Chem Lett 15: 2107-2210.

Wentland MP, Lou R, Lu Q, Bu Y, Denhardt C, Jin J et al (2009). Syntheses of novel high affinity ligands for opioid receptors. Bioorg Med Chem Lett 19: 2289-2294.

Wentland MP, Lou R, Lu Q, Bu Y, VanAlstine MA, Cohen DJ et al (2009). Syntheses and opioid receptor binding properties of carboxamido-substituted opioids. Bioorg Med Chem Lett 19: 203-208.

Zalsman G, Molcho A, Huang Y, Dwork A, Li S, Mann JJ (2005). Postmortem $\mu$-opioid receptor binding in suicide victims and controls. J Neural Transm 112: 949-954.

Zubieta JK, Ketter TA, Bueller JA, Xu Y, Kilbourn MR, Young EA et al (2003). Regulation of human affective responses by anterior cingulated and limbic $\mu$-opioid neurotransmission. Arch Gen Psychiatry 60: 1145-1153.

(i) (-) This work is licensed under a Creative Commons Attribution-NonCommercial-NoDerivs 3.0 Unported License. To view a copy of this license, visit http:// creativecommons.org/licenses/by-nc-nd/3.0/ 